\title{
Growth and Metabolic Response of Suckling Rats Fed with Natural Honey Supplements
}

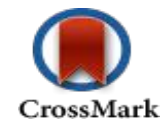

\author{
Abdulwahid Ajibola ${ }^{1 *}$, Jimmy Olusakin², Abdulwaheed A. Oyewale ${ }^{3}$ \\ ${ }^{1}$ Department of Human Physiology, Faculty of Medicine, Kaduna State University, Kaduna, Nigeria \\ ${ }^{2}$ Department of Anatomy, Faculty of Biomedical Sciences, Kampala International University, Western campus, Bushenyi, Kampala, \\ Uganda \\ ${ }^{3}$ Department of Anatomy, Faculty of Medicine, Kaduna State University, Kaduna, Nigeria
}

"Corresponding author: Abdulwahid Ajibola, Department of Physiology, Faculty of Basic Medicine, Kaduna State University, PMB 2339, Kaduna 800001, Kaduna, Nigeria, Tel: +234 8037803988; +234 8055218256; E-mail: ajibola66@gmail.com

\begin{abstract}
The growth and metabolic response of unweaned rats fed with honey were investigated. Ten day old Sprague-Dawley rats were gavaged with $50 \%$ honey solution (low dose $10 \mathrm{ml} / \mathrm{kg}$ or high dose $20 \mathrm{ml} / \mathrm{kg}$ ) twice daily for ten days. All data were expressed as mean \pm SEM and analyzed by one way ANOVA. Pups nourished with honey had 5.41-7.43\% body weight gain than untreated rats. Tibial length was significantly increased $(\mathrm{p}<0.05)$ in the honey-fed group than control $(6-9 \%)$. The differences in growth could be attributed to circulating insulin-like growth factor-1 as the concentrations were also significantly higher in the honey-fed pups. There were no differences in the circulating and stored metabolic substrates (glucose, triglycerides, free fatty acid, cholesterol, lipid and glycogen) between the treatment and control groups. The plasma alanine transaminase was not affected by the treatments, however there was significantly increased plasma alkaline phosphatase activity in the male pups compared with female litter mates. Short term (10-day) oral administration of honey resulted in growth promotion and increased alkaline phosphatase in male rats, possibly in relation to bone growth and caused no liver pathology in neonatal rats. It was concluded that honey supplements administered orally to suckling rats have a positive effect on body weight and linear growth, and these effects are beneficial during weaning and development of fast growing animals.
\end{abstract}

Received Date: December 04, 2015

Accepted Date: February 03, 2016

Published Date: February 08, 2016

Citation: Ajibola, A., et al. Growth and Metabolic Response of Suckling Rats Fed with Natural Honey Supplements. (2016) Int J Food Nutr Sci 3(1): 199-203.

Keywords: Honey; Growth; Insulin like growth factor-1; Metabolic substrates; Liver enzymes; Liver Biomarkers; Suckling rats

DOI: $10.15436 / 2377-0619.16 .041$

\section{Introduction}

Honey has many reported physiological effects and is well adapted to growth in animal models ${ }^{[1-3]}$. It contains more than 300 bioactive substances which include fructose, glucose, proteins, phytochemicals, oligosaccharides, minerals, vitamins and other micronutrients ${ }^{[4]}$. The other constituents of honey are chemical substances, some of which can be absorbed intact from the gastrointestinal tract into the bloodstream where they exert biological effects, such as haemato-protection and immunoregulation ${ }^{[5-7]}$. The anti-hyperglycaemic effects and glycaemic influence of honey in experimental rats ${ }^{[8]}$, make it useful in treating type I and type II diabetes mellitus by reducing the levels of fasting blood sugar ${ }^{[9]}$ as well as increasing plasma insulin levels ${ }^{[10]}$. Honey decreases gastric acid secretion and confers gastro-protection against hydrochloric acid injury, indomethacin and other agents causing gastrointestinal assaults $^{[11]}$. In fact, honey is being exploited as a complementary and alternative medicine (CAM), as the number of investigations into its value as a pharmacological agent increases. Given its many biologically active constituents, honey may have trophic effects and modulate tissue function and structure. Chronic exposure to honey produces various physiological effects including growth and trophic effects on various organs ${ }^{[1,10]}$. Thus, it is important to study the acute effects of honey on the GIT of neonates. 


\section{Materials and Methods}

The study was done following the approval of the Animal Ethics Screening Committee, University of the Witwatersrand, South Africa. The experimental procedures were performed according to local, national and international rules pertaining to animal experiments, clinical studies and biodiversity rights.

\section{Animals and experimental protocols}

Five adult nursing Sprague Dawley female rats that had given birth to a total of 49 suckling pups ( 24 males and $25 \mathrm{fe}-$ males), with body weight of $23.4 \pm 0.33 \mathrm{~g}$ (range 18-26 g) were used for the study. Each dam was housed separately with its respective pups, the treatments were initiated 10 days postpartum whilst the pups remained with their respective dams throughout the study period. The littermate pups were randomly allocated to three treatment groups thus: (group 1, Control $(\mathrm{CON})-$ distilled water; group 2, Natural honey Low (NHL) - $10 \mathrm{ml} / \mathrm{kg}$ of $50 \%$ honey; and Group 3, Natural honey High (NHH) $-20 \mathrm{ml} / \mathrm{kg}$ of $50 \%$ honey. All solutions were administered by gavage via an orogastric tube, and the pups were allowed to suckle ad libitum between gavage. The treatments were administered twice daily at 12 hours interval, every morning $(07 \mathrm{hrs}-08 \mathrm{hrs})$ and evening (19 hrs $-20 \mathrm{hrs)}$ for 10 days. The growth of the experimental animals was monitored daily by measuring body weight.

\section{Tissue collection and analyses}

After 20 days old, the pups were anaesthetised with sodium pentobarbitone $(50 \mathrm{mg} / \mathrm{kg})$ to draw blood by cardiac puncture and then subsequently killed with sodium pentobarbitone $(150 \mathrm{mg} / \mathrm{kg})$ (EUTHANASE ${ }^{\circledR}$, Centaur Labs, Johannesburg, South Africa) injected intraperitoneally. Blood samples were obtained by cardiac puncture using $21 \mathrm{G}$ needles on $1 \mathrm{ml}$ syringes flushed with heparin (Heparin Novo ${ }^{\circledR}$, Novo Nordisk Company, Johannesburg, South Africa). The blood samples were used immediately for determination of glucose, triglycerides and liver enzymes. The samples were transferred to plain blood tubes and then centrifuged at $3000 \mathrm{G}$ at $4^{\circ} \mathrm{C}$ (SorvallRT ${ }^{\circledR} 6000 \mathrm{~B}$ ) for 15 min and the plasma was decanted and stored at $-70^{\circ} \mathrm{C}$ for later clinical biochemistry.

\section{Femur and tibia length and weight}

The rats were dissected to remove the right long bones (femur and tibia) for measurement as indicators of linear growth. The bones were carefully defleshed, and the right femoral head was removed gently from the acetabulum at the hip joint. The muscles and soft tissues were removed from the femur and tibia, and the length of the bones was measured with a thread and metric ruler. In measuring the length of the femur, the femoral neck was used as a reference point to avoid the effect of anatomy of the femoral head on the measurements. The bones were then dried at $40^{\circ} \mathrm{C}$ for 7 days in a Salvis vacucenter oven (Oakton $\AA$, USA), and then weighed using a Precisa $310 \mathrm{M}$ digital balance (Precisa ${ }^{\circledR}$, Vadodara, Switzerland) until constant weight was obtained. The density was then estimated by the formula of Monteagudo, et al. 1997 thus: Bone density $(\mathrm{mg} / \mathrm{mm})=$ dry bone weight $(\mathrm{mg}) /$ bone length $(\mathrm{mm})^{[12]}$.

\section{Metabolic substrates in blood, liver enzymes, liver biomark-} ers and IGF-1

The blood glucose and triglyceride concentrations were determined by use of a glucometer (Glucometer Elite $\AA$, Bayer Company, Japan) on glucose test strips (Ascensia Elite ${ }^{\circledR}$, Bayer (PTY) Ltd, South Africa); and triglyceride meter (Accutrend ${ }^{\circledR}$ Cobas, Roche Company, Germany) on TG test strips (Roche Diagnostics, Germany). Free fatty acids (FFAs) in the plasma samples of the pups were determined colorimetrically using FFAs Half-micro test kit (Roche Diagnostics, Germany). Liver enzymes (ALP and ALT) and the other liver biomarkers (cholesterol and total bilirubin) were also obtained colorimetrically from the plasma using the specific health profile discs on Vet Test Chemistry Analyzer (Idexx Laboratories Inc, Diamond Diagnostics Holliston, USA).

The hormone IGF-1 was determined by enzyme linked immunosorbent assay (ELISA) using a Mouse IGF-1 kit per manufacturer's instruction (Quantikine $\AA$, Mouse IGF1, R\&D Systems Europe). The kit also recognises rat IGF-1 which shares 99\% amino acid sequence identity with mouse IGF-1 and the kit has been validated for the determination of rat IGF-1. The sample values were read on a plate reader machine (Multiskan Ascent, Lab system, model no 354, Helsinki, Finland) at 450 $\mathrm{nm}$ with a second correction wavelength measurement at 540 $\mathrm{nm}$. A standard curve was constructed and the concentrations of the IGF-1 in the samples were determined with reference to the standard curve.

\section{Liver weight, Liver lipid and glycogen content}

The liver weight was obtained according to standard procedure. The lipid extraction was done using the method of Bligh and Dyer (1959) ${ }^{[13]}$. Briefly, 0.5g of the frozen liver samples were thawed, finely chopped with a scalpel blade and then mixed in $100 \mathrm{ml}$ of chloroform-methanol mixture $(2: 1)$ and left to extract overnight at $4^{\circ} \mathrm{C}$. The samples were then filtered through filter paper (Albert $\AA$, Pore $7-11$, Size $185 \mathrm{~mm}$ ), $30 \mathrm{ml}$ $0.9 \%$ saline added, mixed, and allowed to stand overnight at $4^{\circ} \mathrm{C}$. The bottom (chloroform) phase was collected and reduced to dryness under vacuum at $37^{\circ} \mathrm{C}$ and re-dissolved in $20 \mathrm{ml}$ chloroform. $2 \mathrm{ml}$ aliquots were each placed in a dried, pre-weighed vial, and re-dried at $50^{\circ} \mathrm{C}$ for 30 minutes, cooled and then reweighed to determine the lipid content. The residues from the liver samples (post lipid extraction) were also dried and their dry matter content determined.

The glycogen content of the liver was determined indirectly ${ }^{[14]}$. Briefly, $0.1 \mathrm{~g}$ of the liver was placed in $1 \mathrm{ml}$ of $0.03 \mathrm{M}$ hydrochloric acid and homogenised with an ultra turrex homogeniser for 20 seconds. To hydrolyse the glycogen, $1 \mathrm{ml}$ of $1 \mathrm{M}$ hydrochloric acid was added to the homogenate and the mixture placed in sealed tubes in a boiling water bath for 2 hours. One $\mathrm{ml}$ of $1 \mathrm{M}$ sodium hydroxide was added to neutralise the acid. Glucose content of the solution was determined via a glucose assay kit (Sigma catalogue, GAGO-20) and the glycogen expressed as glucose equivalents $(\mathrm{mmol} / \mathrm{g})$.

\section{Statistical analyses}

The results were expressed as mean \pm SEM. GraphPad Prism version 5.02 (GraphPad, San Diego, CA) was used for data analyses. The data were analysed by one-way analysis of variance (ANOVA) with Neuman-Keul's post hoc used as a mul- 
tiple comparison test. The level of significance was set at a $p$ value of less than $0.05(p<0.05)$, except otherwise stated.

\section{Results}

Table 1 showed the proximate analyses of the natural honey used as the dietary supplements. All animals remained healthy during the study and no incidental or iatrogenic mortalities were recorded. There was no difference in the initial body weight of the suckling rats (Figure 1). All rats gained weight significantly $(\mathrm{p}<0.001)$ after 10 days of treatments (Figure 1), but with slight increased final body weights of the honey-fed $(5.41-7.43 \%)$ relative to controls.

Table 1: Nutritional profile of natural honey used as supplements (Mean $\pm \mathrm{SEM}$ ).

\begin{tabular}{|l|c|}
\hline Proximate Analyses & Amount \\
\hline Water $(\%)$ & $15.92 \pm 0.07$ \\
\hline Carbohydrate $(\mathrm{g} / 100 \mathrm{~g})$ & $88.97 \pm 1.71$ \\
\hline Fructose $(\mathrm{g} / 100 \mathrm{~g})$ & $43.35 \pm 0.02$ \\
\hline Glucose $(\mathrm{g} / 100 \mathrm{~g})$ & $37.64 \pm 0.01$ \\
\hline Sucrose $(\mathrm{g} / 100 \mathrm{~g})$ & $2.03 \pm 0.05$ \\
\hline Maltose $(\mathrm{g} / 100 \mathrm{~g})$ & $2.75 \pm 0.02$ \\
\hline Protein $(\%)$ & $0.42 \pm 0.06$ \\
\hline Fat $(\%)$ & $0.53 \pm 0.01$ \\
\hline Glycaemic sugars $(\%)$ & $76.71 \pm 1.55$ \\
\hline Energy $(\mathrm{MJ} / \mathrm{Kg})$ & $15.56 \pm 0.21$ \\
\hline Other nutrients $(\%)$ & $0.53 \pm 0.00$ \\
\hline
\end{tabular}

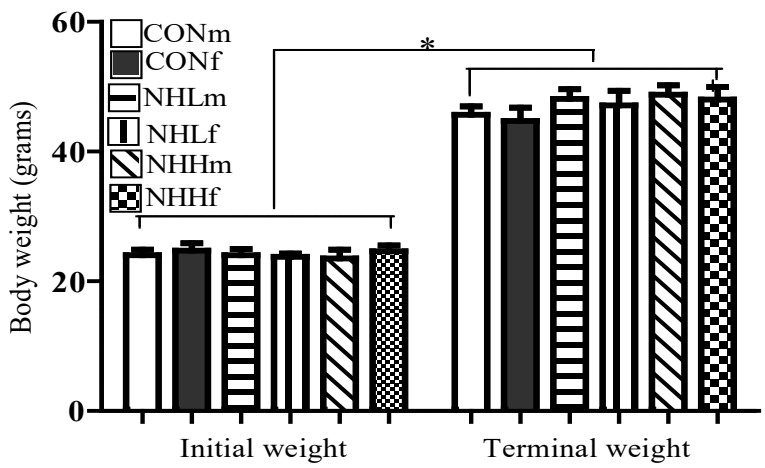

Figure 1: Effects of treatment diets on body weight gain of suckling male rats at 20 days of age. CONm, control male ( $\mathrm{n}=7$ ); CONf, control female $(n=7)$; NHLm, natural honey low dose male $(n=8)$; NHLf, natural honey low dose female $(n=9)$; NHHm, natural honey high dose male $(n=9)$; NHHf, natural honey high dose female $(\mathrm{n}=9)$. *Significant increase $(\mathrm{P}<0.001$, ANOVA) in body weight gain for all groups after 10 -day treatment vs initial weight.

There was no difference $(p>0.05)$ in linear growth of the treatment femurs and controls (Table 2). However, the honey-fed rats had significantly $(\mathrm{p}<0.05)$ longer tibias than the controls $(6-9 \%)$, but there was no difference in the tibial weights between the treatment and control rats (Table 2).

Table 2: Weight, length, and bone density $(\mathrm{mg} / \mathrm{mm})$ of the femur and tibia of 20-day old male and female suckling rats after 10 days of honey supplements (Mean \pm SEM).

\begin{tabular}{|c|c|c|c|c|c|c|c|}
\hline & & \multicolumn{3}{|c|}{ Femur } & \multicolumn{2}{c|}{ Tibia } \\
\hline Diet & Sex & Weight $(\mathrm{mg})$ & Length $(\mathrm{mm})$ & Density $(\mathrm{mg} / \mathrm{mm})$ & Weight $(\mathrm{mg})$ & Length $(\mathrm{mm})$ & Density $(\mathrm{mg} / \mathrm{mm})$ \\
\hline CON & M & $65.3 \pm 2.32$ & $15.0 \pm 0.26$ & $4.35 \pm 0.12$ & $51.3 \pm 1.67$ & $17.1 \pm 0.21$ & $2.91 \pm 0.10$ \\
\hline & F & $67.3 \pm 1.74$ & $14.9 \pm 0.26$ & $4.54 \pm 0.14$ & $51.6 \pm 2.17$ & $17.6 \pm 0.20$ & $2.94 \pm 0.14$ \\
\hline NHL & M & $66.9 \pm 1.46$ & $15.1 \pm 0.28$ & $4.45 \pm 0.08$ & $53.1 \pm 1.36$ & $18.6 \pm 0.22$ & $2.87 \pm 0.09$ \\
\hline & F & $65.7 \pm 2.02$ & $14.9 \pm 0.46$ & $4.42 \pm 0.14$ & $52.7 \pm 2.13$ & $18.6 \pm 0.20$ & $2.85 \pm 0.11$ \\
\hline NHH & M & $64.8 \pm 2.56$ & $14.9 \pm 0.28$ & $4.33 \pm 0.10$ & $53.9 \pm 3.44$ & $18.7 \pm 0.28$ & $2.90 \pm 0.17$ \\
\hline & F & $65.2 \pm 3.30$ & $14.8 \pm 0.40$ & $4.38 \pm 0.12$ & $53.5 \pm 2.29$ & $18.5 \pm 0.34$ & $2.89 \pm 0.09$ \\
\hline
\end{tabular}

no significant difference $(\mathrm{p} \geq 0.05)$ in weight, length, and density of the long bones amongst the control and treatment groups, except longer tibia of honey-fed rats than control. 
The plasma concentrations of circulating metabolic substrates were similar for all the groups (not shown). Similarly, no significant difference was observed in the liver lipids and hepatic glycogen of the suckling pups after 10-day treatment (not shown). There were no differences in the liver biomarkers except the significantly higher $(\mathrm{p}<0.05)$ IGF-1 values in the honey-fed than control pups (Table 3). For the alkaline phosphatase (ALP), there was significant elevation $(p<0.05)$ in males than female rats (Table 3 ).

Table 3: Surrogate markers of liver function in 20-day old male and female suckling rats after feeding with honey supplements for 10 days.

\begin{tabular}{|c|c|c|c|c|c|}
\hline Diet & Sex & ALT (U/L) & ALP (U/L) & $\begin{array}{c}\text { Tbil } \\
(\mu \mathrm{mol} / \mathrm{L})\end{array}$ & $\begin{array}{c}\text { IGF-1 }(\mathrm{pg} / \\
\mathrm{ml})\end{array}$ \\
\hline CON & $\mathrm{M}$ & $26.0 \pm 3.4$ & $399.2 \pm 40.9$ & $6.0 \pm 1.4$ & $130.9 \pm 3.4$ \\
\hline & $\mathrm{F}$ & $26.8 \pm 5.0$ & $320.5 \pm 30.7^{\beta}$ & $7.7 \pm 3.1$ & $131.4 \pm 2.5$ \\
\hline $\mathrm{NHL}$ & $\mathrm{M}$ & $27.2 \pm 5.4$ & $381.7 \pm 7.7$ & $5.0 \pm 0.7$ & $155.8 \pm 6.7^{*}$ \\
\hline & $\mathrm{F}$ & $28.0 \pm 3.5$ & $341.4 \pm 18.9^{\beta}$ & $5.6 \pm 1.0$ & $159.3 \pm 3.3^{*}$ \\
\hline $\mathrm{NHH}$ & $\mathrm{M}$ & $27.1 \pm 2.6$ & $434.7 \pm 31.1$ & $6.2 \pm 1.0$ & $164.8 \pm 5.7^{*}$ \\
\hline & $\mathrm{F}$ & $30.3 \pm 2.0$ & $363.8 \pm 23.0^{\beta}$ & $5.1 \pm 0.5$ & $162.4 \pm 7.6^{*}$ \\
\hline
\end{tabular}

${ }^{*}$ significantly higher than control $(\mathrm{p}<0.05) ;{ }^{\beta}$ significantly lower than corresponding male values $(\mathrm{p}<0.05) ;$ ALT $=$ alanine transaminase; ALP $=$ alkaline phosphatase; $\mathrm{T}$ bil = total bilirubin; IGF-1 = Insulin like growth factor-1

\section{Discussion}

The rate of growth and development of rat pups can be greatly altered by varying supplements administered to them during the suckling period ${ }^{[15]}$. The results indicated that dietary enrichment by oral administration of natural honey to suckling rats positively influenced growth. Tibial length has been used as a more accurate indicator of linear growth compared to body weight gain ${ }^{[16,17]}$, which can be influenced by several factors such as food intake, obesity and hydration status ${ }^{[18,19]}$. The elongated tibias of the honey-fed pups in this study (Table 2) confirmed the trophic effects of natural honey. Growth hormone $(\mathrm{GH})$ is a key hormone for promotion of growth and development ${ }^{[20]}$. However, GH mediates its growth promoting effects directly by stimulating protein deposition in the body and bone and visceral growth ${ }^{[20]}$ and indirectly via stimulation of somatomedins (IGF-I and IGF-II) production. The indirect GH action via IGF-1 is thought to be the major mechanism for its effects ${ }^{[21]}$. Hence, the IGF-1 hormonal assay in the experimental pups, whose value increased as honey intake was increased (Table 3). The elevated IGF-1 values of the treatment groups further strengthened the trophic effect on the tibias due to honey consumption, as this hormone, IGF-1 is known to promote long bone and tissue growth ${ }^{[22]}$. The linear growth of these honey-fed neonates aligned with the observation of Ajibola and other workers in previous studies on adult and weaned rodents ${ }^{[1,6]}$.

The liver plays an important role in metabolism to maintain energy levels. The blood concentration of glucose in young rats is maintained at a fairly constant level from 2 to 20 days after birth ${ }^{[23]}$. The glucose level in non-fasting blood after 10 days of treatment with honey supplements did not show any significant differences between the groups. This suggests that the honey supplements did not affect endocrine pancreatic func- tion. Fatty acids will accumulate in the liver unless the rate of export in plasma lipoproteins or oxidation $\mathrm{CO}_{2}$ is increased ${ }^{[24]}$. The values of the metabolic substrates in circulation and storage (not shown) in these pups was a reflection homeostasis within the rats' systems. The liver is prone to damage as a consequence of exposure to toxins as the primary metabolic and detoxification centre in the body ${ }^{[25]}$. Alkaline phosphatase (ALP) and alanine transaminase (ALT) are important markers of liver damage hence their plasma concentrations were used to assess the hepatotoxicity of the honey supplements. No significant differences in ALT were detected (Table 3). Indeed, previous studies in weaned and adult rats show that honey could be gastro- and hepato-protective ${ }^{[11,26]}$, due to its antioxidant constituents ${ }^{[4]}$. The blood concentrations of ALP were significantly elevated in the male rats relative to their female litter mates. Although circulating ALP elevations are usually associated with bile duct damage/ bile stasis, ALP is also released from bone following pathology or excessive remodelling as during rapid growth as in this study.

\section{Conclusion}

Honey supplements administered orally to suckling rats have a positive effect on body weight and linear growth in the short term. These effects could be useful in preventing weight loss during weaning and bone disturbances during development of fast growing animals. The results of this neonatal study aligned with our previous reports of the beneficial health effects of acute and chronic administration of honey. There is however a need to have mechanistic insights into honey's actions. Future neonatal studies should be undertaken with broader range of parameters assessed to determine the functional significance of the effects of honey, with a view to identify the specific chemical component(s) of honey inducing the changes.

\section{Acknowledgement}

This study was partly funded by the Tertiary Education Trust Fund (TETFund), Abuja, Nigeria. The work was also supported by grants from the National Research Foundation (NRF) of South Africa; the University of the Witwatersrand; and the Faculty of Veterinary Science, University of Pretoria. University of the Witwatersrand, South Africa provided the experimental animals. Prof. Kennedy Erlwanger of School of Physiology, University of the Witwatersrand is appreciated for making his laboratory available for the research. The authors also expressed their appreciation to Ms. Janine Donaldson, Ms. Rachael Dangarembizi, Mr. Busisani Lembede and Mr. Owen Karimanzira for their technical assistance.

\section{References}

1. Ajibola, A., Chamunorwa, J.P., Erlwanger, K.H. Dietary supplementation with natural honey promotes growth and health of male and female rats compared to cane syrup. (2013a) Scientific Research and Essays 8(14): 543-553.

2. Ajibola, A. Novel insights into the health importance of natural honey. (2015) Malaysian Journal of Medical Science 22(5): 7-22.

3. Chepulis, L., Starkey, N. The long-term effects of feeding honey compared to sucrose and a sugar-free diet on weight gain, lipid profiles, and DEXA measurements in rats. (2008) J Food Sci 73(1): H1-7.

4. Bogdanov, S., Jurendic, T., Sieber, R.,et al. Honey for nutrition and health: A review. (2008) J Am Coll Nutr 27(6): 677-689. 
5. Al-Waili, N.S. Effects of daily consumption of honey solution on hematological indices and blood levels of minerals and enzymes in normal individuals. (2003) J Med Food 6(2): 135-140.

6. Ajibola, A., Idowu, G.O., Amballi, A.A., et al. Improvement of some haematological parameters in albino rats with pure natural honey. (2007) Journal of Biological Science Research 2: 67-69.

7. Chepulis, L.M. The effects of honey compared with sucrose and a sugar-free diet on neutrophil phagocytosis and lymphocyte numbers after long-term feeding in rats. (2007) Journal of Complementary and Integrative Medicine 4(1): 1-9.

8. Ajibola, A., Chamunorwa, J.P.,Erlwanger, K.H. Metabolic health of growing male and female rats on long-term dietary supplementation with natural honey compared to cane syrup. (2015) Applied Physiology, Nutrition, and Metabolism.

9. Erejuwa, O.O. Effect of honey in diabetes mellitus: matters arising. (2014) J Diabetes Metab Disord 13(1): 23.

10. Ajibola, A., Chamunorwa, J.P.,Erlwanger, K.H. Comparative effects of dietary supplementation with natural honey and cane syrup on the morphometry of viscera in growing male and female rats.(2013b) Indian Journal of Experimental Biology 51: 303-312.

11. Gharzouli, K., Amira, S., Gharzouli, A.,et al. Gastro protective effects of honey and glucose-fructose-sucrose-maltose mixture against ethanol-, indomethacin-, and acidified aspirin induced lesions in the rat. (2002) Exp Toxicol Pathol 54(3): 217-221.

12. Monteagudo, M.D., Hernandez, E.R., Seco, C., et al. Comparison of the bone robusticity index and bone weigth/bone length index with the results of bone densitometry and bone histomorphometry in experimental studies. (1997) Acta Anat (Basel) 160(3): 195-199.

13. Bligh, E.G., Dyer, W.J.A rapid method of total lipid extraction and purification. (1959) Canadian Journal of Biochemistry and Physiology 37(8): 911-917.

14. Passoneau, J.V., Lauderdale V.R. A comparison of three methods of glycogen measurement in tissues. (1974) Analytical Biochemistry 60(2): 405-412.

15. Heidi, H., Swamson, P., Bolwerk, E., et al. Effects of cooling in infant rats on growth, maturation, sleep patterns and responses to food deprivation. (1984) British Journal of Nutrition 52(1): 139-148.
16. Tjaderhane, E.B.L., Larmas, M. A high sucrose diet decreases the mechanical strength of bones in growing rats. (1998) Journal of Nutrition 128(10): 1807-1810

17. Fritton, J.C., Myers, E.R., Wright, T.M. et al. Loading induces site specific increases in mineral content assessed by micro-computed tomography of the mouse tibia. (2005) Bone 36(6): 1030-1038.

18. Deng, H., Lai, D., Conway, T., et al. Characterization of genetic and lifestyle factors for determining variation in body mass index, fat mass, percentage of fat mass and lean mass. (2001) J Clin Densitom 4(4): 353-361.

19. Eshet, R., Maor, G., Ari, B.T., et al. The aromatase inhibitor letrozole increases epiphyseal growth plate height and tibial length in peripubertal male mice. (2004) J Endocrinol. 182(1): 165-172.

20. Tisi, D.K., Liu, X.J., Wykes, L.J, et al. Insulin-like Growth Factor II and binding proteins 1 and 3 from second trimester human amniotic fluid are associated with infant birth weight. (2005) J Nutr 135(7): $1667-1672$.

21. Baroncelli, G. I., Bertelloni, S., Sodini, F.,et al. Acquisition of bone mass in normal individuals and in patients with growth hormone deficiency. (2003) J Pediatr Endocrinol Metab 16(Suppl 2): 327-335.

22. Sonntag, W.E., Ramsey, M., Carter, C.S. Growth hormone and insulin-like growth factor-1 (IGF-1) and their influence on cognitive aging. (2005) Ageing Res Rev 4(2): 195-212.

23. Innis, S.M. The role of diet during development on the regulation of adult cholesterol homeostasis. (1985) Canadian Journal of Physiology and Pharmacology 63(5): 557-564.

24. Erol, E., Kumar, L.S., Cline, G.W., et al. Liver fatty acid-binding protein is required for high rates of hepatic fatty acid oxidation but not for the action of PPAR- $\alpha$ in fasting mice. (2004) FASEB J 18(2): 347349 .

25. Gaskill, C.L., Hoffman, W.E.,Cribb, A.E. Serum alkaline phosphatase isoenzyme profiles in Phenobarbital-treated epileptic dogs. (2004) Veterinary Clinical Pathology 33(4): 215-222.

26. Ajibola, A., Chamunorwa, J.P., Erlwanger, K.H. Nutraceutical values of natural honey and its contribution to human health and wealth. (2012) Nutr Metab (Lond) 9: 61
Online ISSN: 2377-0619

Journal Title: International Journal Food and Nutritional Science Journal Short Name: Int J Food Nutr Sci
Ommega Online Publishers

E-mail: foodscience@ommegaonline.org

Website: www.ommegaonline.org 